\title{
A DANÇA E A EXPRESSÃO CORPORAL COMO MEDIADORAS NO PROCESSO DE ENSINO-APRENDIZAGEM DE CRIANÇAS COM DE- FICIÊNCIA INTELECTUAL E TRANSTORNOS DE APRENDIZAGEM
}

\author{
Keyla Ferrari Lopes \\ Universidade Estadual de Campinas, Campinas, São Paulo, Brasil. \\ Camila Lopes de Carvalho \\ Universidade Estadual de Campinas, Campinas, São Paulo, Brasil. \\ Paulo Ferreira de Araújo \\ Universidade Estadual de Campinas, Campinas, São Paulo, Brasil. \\ Maria Aparecida Affonso Moysés \\ Universidade Estadual de Campinas, Campinas, São Paulo, Brasil.
}

\begin{abstract}
Resumo
Esse estudo objetivou verificar contribuições das atividades de dança e expressão corporal ao processo de ensino-aprendizagem de alunos com deficiência intelectual e transtornos de aprendizagem. Para isso, foram realizadas entrevistas semiestruturadas com as mães e a professora de dança de duas crianças de sexo masculino, com onze anos, uma com deficiência intelectual e outra com transtornos de aprendizagem, que participaram regularmente de atividades de dança e expressão corporal, antes e após seis meses de prática. Como resultado, foi identificado que as atividades possibilitaram desenvolvimento do processo de ensino-aprendizado das crianças e a exploração de potenciais comumente não identificados em outros contextos de ensino.
\end{abstract}

Palavras-chave: Dança. Deficiência Intelectual. Transtornos de Aprendizagem.

\section{DANCE AND BODY EXPRESSION AS MEDIATORS IN THE TEACHING- LEARNING PROCESS OF CHILDREN WITH INTELLECTUAL DISABILITIES AND LEARNING DISORDERS}

\begin{abstract}
This study analyzes contributions of dance and body expression activities to the learning process of students with intellectual disabilities and learning disorders. For that, semi-structured interviews were conducted with the mothers and the dance teacher of two male children, aged eleven years, one with intellectual disability and another with learning disorders, who regularly participated in dance and body expression activities, before and after six months of practice. It was identified development of the children's learning and the exploration of potentials not commonly identified in other contexts of teaching.
\end{abstract}

Keywords: Dancing. Intellectual Disability. Learning Disorders. 


\title{
LA DANZA Y LA EXPRESIÓN CORPORAL COMO MEDIADORAS EN EL PROCESO DE ENSEÑANZA-APRENDIZAJE DE NIÑOS CON DISCAPACIDAD INTELECTUAL Y TRAS- TORNOS DEL APRENDIZAJE
}

\begin{abstract}
Resumen
Este estudio objetivó verificar contribuciones de las actividades de danza y expresión corporal al proceso de enseñanza aprendizaje de alumnos con discapacidad intelectual y trastornos del aprendizaje. Para ello, se realizaron entrevistas semiestructuradas con las madres y la profesora de danza de dos niños de sexo masculino, con once años, una con discapacidad intelectual y otra con trastornos del aprendizaje, que participaron regularmente de actividades de danza y expresión corporal, antes y antes, Después de seis meses de práctica. Como resultados, se identificó que las actividades posibilitar el desarrollo del proceso de enseñanza aprendizaje de los niños y la explotación de potenciales comúnmente no identificados en otros contextos de enseñanza.
\end{abstract}

Palabras clave: Baile. Discapacidad Intelectual. Trastornos del Aprendizaje.

\section{Introdução}

A atribuição de denominações para as pessoas que apresentam dificuldades ou atrasos no seu desenvolvimento transformou-se ao longo da história de acordo com a concepção de homem, de sociedade e de trabalho. Sassaki (2005), Shimazaki e Tsukamoto (2012) apontaram que essas pessoas já receberam denominações como retardadas, oligofrênicas, cretinas, imbecis, idiotas, débeis e subnormais em períodos nos quais a causa e a condição não eram de todo compreendidas cientificamente e as explicações místicas predominavam.

A partir do século XX, houve a estruturação social de um cientificismo fundamentado, inicialmente, no determinismo que propagava a necessidade de adaptação biológica dos indivíduos às transformações contínuas do ambiente para que estes pudessem ser aptos à vida em sociedade. Principiaram-se classificações individuais para avaliar os capazes de contribuir ou não socialmente com uma tendência de graduação - ordenação de coisas em escalas ascendentes - e de reificação - tentativa de mensurar o abstrato, como a inteligência (GOULD, 1991; HARLOS; HARLOS; DENARI, 2012).

Dessa forma, testes foram elaborados para tentar quantificar o funcionamento cognitivo e identificar a presença de desvios intelectuais. Gould (1991) afirmou que, inicialmente, tais testes foram fundamentados em uma abordagem psicométrica, com a craniometria estabelecendo correlações entre o tamanho de partes do corpo, como a circunferência craniana, e a quantidade de inteligência apresentada por uma pessoa. Na sequência, foram propostos testes de inteligência com perguntas a serem respondidas com base em raciocínio lógico-matemático e linguístico.

No entanto, Leontiev (1991) relatou que os resultados dessas avaliações forneciam somente informações superficiais, sem discorrerem sobre a natureza nem sobre uma interpretação absoluta de um possível atraso identificado. De forma complementar, essas críticas foram reforçadas por Carvalho, Araújo e Salerno (2013) ao explicitarem que equívocos permeavam estes procedimentos, como ao considerar a inteligência algo inato e não em desenvolvimento, além de os testes serem estruturados com conceitos específicos de determinadas sociedades, desconsiderando as diversidades culturais nas respostas.

A datar da segunda metade do século XX, com o desenvolvimento da ciência interacionista e um entorno social de defesa e de valorização dos direitos humanos, culminou-se no entendimento de essas condições fazerem parte de um quadro denominado de Transtornos do 
Neurodesenvolvimento, o qual, segundo o Diagnostic and Statistical Manual of Mental Disorders (DSM-5), engloba prejuízos no âmbito do desenvolvimento pessoal, acadêmico, profissional ou em demais contextos sociais. Dentre as condições inclusas nesse quadro, destacase a Deficiência Intelectual e os Transtornos de Aprendizagem.

Acerca da deficiência intelectual, no ano de 1992, a Associação Americana de Retardo Mental (AAMR), hoje denominada de Associação Americana em Deficiência Intelectual e do Desenvolvimento (AAIDD), afirmou:

\begin{abstract}
Refere a limitações substanciais no funcionamento atual dos indivíduos sendo caracterizado por um funcionamento intelectual significativamente abaixo da média, existindo concomitante com relativa limitação associada a duas ou mais área de condutas adaptativas, indicadas a seguir: comunicação, autocuidado, vida no lar, habilidades sociais, desempenho na comunidade, independência na locomoção, saúde e segurança, habilidades acadêmicas funcionais, lazer e trabalho. A deficiência intelectual se manifesta antes dos 18 anos. (LUCKASSON et al., 1992, p. 11).
\end{abstract}

Ao analisar essa acepção, Almeida (2004) refletiu que a mesma ainda se pautava em resquícios da mensuração da inteligência. Todavia, apresentava contribuições ao delimitar uma idade para a manifestação da condição e critérios para o diagnóstico da sua ocorrência.

Em 2002, a AAIDD apresentou uma nova conceituação:

Uma incapacidade caracterizada por limitações significativas em ambos, funcionamento intelectual e comportamento adaptativo e está expresso nas habilidades sociais, conceituais e práticas. A incapacidade se origina antes da idade de 18 anos. (LUCKASSON et al., 2002, p. 08).

Essa terminologia de deficiência intelectual foi consolidada a partir da publicação da Declaração de Montreal sobre a Deficiência Intelectual, proposta pela Organização Mundial da Saúde (OMS) e pela Organização Pan-Americana de Saúde (OPS), no ano de 2004, a qual apontou que essa denominação deveria ser reconhecida internacionalmente como a adequada, bem como "os valores universais de dignidade, autodeterminação e igualdade" para todos que a possuíssem (OMS, 2004, p. 2).

Por esse documento, também foi expressa uma discordância em relação à continuidade do emprego da expressão de deficiência mental, uma vez que esta poderia gerar uma confusão de concepções já que a deficiência intelectual se refere a um comprometimento da função cognitiva e o termo de deficiência mental poderia induzir ao equivocado entendimento presente no conceito de doença mental, no qual ocorrem transtornos mentais necessitários de tratamentos médicos (PUTTINI; JUNIOR, 2007).

$\mathrm{Na}$ data de 2007, essa Associação reformulou novamente seu conceito sobre essa deficiência, apresentando-a como:

Uma incapacidade caracterizada por limitações significativas tanto no funcionamento intelectual (raciocínio, aprendizado, resolução de problemas) quanto no comportamento adaptativo, que cobre uma gama de habilidades sociais e práticas do dia a dia. Esta deficiência se origina antes da idade de 18. (SHOGREN et al., 2010, p. 6).

Sobre influência desses documentos internacionais, no contexto brasileiro a legislação absorveu esse paradigma social da deficiência em contraposição ao anterior conceito médico, estabelecendo, no Documento Subsidiário à Política Nacional de Inclusão (PAULON, 2007, p. 13), a deficiência intelectual como "a incapacidade caracterizada por limitações significativas tanto no funcionamento intelectual quanto no comportamento adaptativo expresso em habilidades conceituais, sociais e práticas". 
Nesta conjuntura, o comportamento adaptativo abarcou uma constelação de habilidades que permitem às pessoas se adaptarem efetivamente nas atividades diárias, em casa, na escola, no trabalho e na comunidade (OAKLAND; HARRISON, 2008), ou seja, um conjunto de habilidades conceituais, sociais e práticas que as pessoas utilizam no seu cotidiano (AAIDD, 2010, p. 15).

Já os Transtornos de Aprendizagem foram entendidos como déficits na percepção ou no processamento e utilização de informações durante um processo de aprendizado, gerando comprometimento no mesmo (AMERICAN PSYCHIATRIC ASSOCIATION, 2014).

Baseado nas concepções acima apresentadas, averigua-se que a deficiência intelectual e os transtornos de aprendizagem são condições relativas, pois a existência de alguma limitação funcional apenas caracteriza um diagnóstico de deficiência se houver um mecanismo social que atribua a essa limitação um valor depreciativo.

Mesmo sendo condições diferenciadas, tanto a deficiência intelectual quanto as dificuldades de aprendizagem encontram semelhanças em suas formas de detecção, que geralmente ocorrem nos espaços de ensino-aprendizado pelo professor.

Contudo, Mantoan (2007) explicou que, apesar de consolidado legalmente no âmbito socioeducacional o discurso de respeito às diferenças e especificidades de cada pessoa ou educando, os contextos de práticas sociais e educativas da contemporaneidade ainda valem-se de métodos desiguais, classificatórios e competitivos, rotulando os que não respondem aos métodos tradicionais em vista da sua incapacidade e negligenciando suas potencialidades.

Neste sentido, as expressões artísticas apresentam-se como um caminho que aproxima e acolhe as pessoas com diferentes habilidades, possibilitando múltiplas formas de interações, contato e conhecimento que poderão ser expressos de acordo com as motivações pessoais, culturais e de identidade. Entre as diversas expressões artísticas, a dança e a expressão corporal, ao lado do teatro e da música, são duas das principais artes cênicas presentes na sociedade, se caracterizando por utilizarem movimentos corporais previamente estabelecidos (coreografia) ou improvisados (dança livre), por meio de passos cadenciados executados ao som e compasso de uma música, com a expressão de sentimentos por ela potencializados.

A expressão corporal é uma atividade artística que se baseia primordialmente no movimento, no gesto e também na quietude do corpo. Ela nasce de sentimentos, sensações, imagens e ideias, se baseia na percepção dos sentidos e na motricidade, integrando as áreas motoras e psíquicas do ser humano. Tanto a dança quanto a expressão corporal possuem a finalidade de auxiliar os praticantes a desenvolverem seus potenciais de movimento e suas habilidades artísticas expressivas. Elas possuem foco principal na capacidade e não na limitação de um indivíduo, promovendo uma constante reavaliação de valores, crenças e atitudes pessoais e sociais em relação às semelhanças e diferenças humanas (ALESSI; ZOLBROD, 2011).

Segundo Laban (1990), a dança permite a ocorrência de uma integração entre o conhecimento intelectual de um indivíduo e suas habilidades criativas, enfatizando a expressão, a espontaneidade e a criatividade. Ainda segundo o autor, ela possui dois valores educativos principais, sendo um a predominância de um movimento saudável e o outro o alcance da harmonia pessoal e social.

Por sua vez, Barreto (2004) acreditou na dança como um meio de comunicação e transmissão de ideias, de fala e de expressão sobre as diferenças, como possibilidade de movimentos para além de corpos, de formas e de técnicas perfeitas. $\mathrm{O}$ autor discorreu que na dança os corpos se expressam com prazer, valorizando sua essencialidade, quebrando ideias ultrapassadas, superando padrões de criações já estabelecidos e recriando novas realidades corpóreas.

Ao complementar esta perspectiva, Kunz (2006) descreveu essa prática como um trabalho com movimentos corporais que auxilia na construção e reconstrução de identidades, de percepção e entendimento de si e do outro. Assim, a dança cria possibilidades de construir 
relações de interação, oportunizando o conhecimento do próprio corpo e de suas possibilidades como forma de compreensão crítica e sensível de si mesmo e do cotidiano que os rodeia.

Considerando a importância de viabilizar novas formas de potencialização do desenvolvimento do aprendizado tanto das pessoas com deficiência intelectual quanto com dificuldades de aprendizagem, tendo em vista a carência de ações eficazes já relatadas com essa prática e almejando as possibilidades contidas nas atividades artísticas, o presente artigo objetivou analisar a contribuição das atividades de dança e expressão corporal para o desenvolvimento do processo de ensino-aprendizagem de crianças com deficiência intelectual e transtornos de aprendizagem.

\section{Metodologia}

Foi realizado um estudo qualitativo, aprovado pelo Comitê de Ética em Pesquisa da Universidade Estadual de Campinas, com parecer número 2.050.058, no qual foram realizadas entrevistas com as mães e as professoras de dança e expressão corporal de duas crianças nos seus primeiros seis meses de aulas.

Para isso, foram selecionadas duas crianças de mesmo gênero, masculino, e mesma faixa etária, 11 (onze) anos de idade, uma delas com deficiência intelectual e síndrome de Down (C1), e a outra com transtornos de aprendizagem (C2).

Ambas iniciaram aulas de dança e expressão corporal na Cia de Dança Humaniza, em Campinas, São Paulo, local que oferece dança e atividades de expressão corporal sob a forma de aulas, mostras e espetáculos para pessoas com e sem deficiência, conjuntamente, conduzidas por profissionais especialistas na dança e no movimento de pessoas com deficiências. A Companhia possui o reconhecimento do Conselho Internacional de Dança da Organização das Nações Unidas para a Educação, Ciência e Cultura (CID UNESCO).

As atividades foram realizadas duas vezes por semana, com um grupo composto de crianças de faixa etária compreendida entre nove e 13 anos de idade. As crianças deste grupo participaram de uma apresentação aberta ao público no final dos seis meses de atividades.

Os responsáveis das crianças foram convidados a participar dessa pesquisa, assim como a professora da Cia, os quais, após consentirem, assinaram o Termo de Consentimento Livre e Esclarecido (TCLE) autorizando o uso dos dados para fins acadêmicos. Dessa forma, os pesquisadores realizaram entrevistas semiestruturadas com as mães das crianças e a professora da dança e expressão corporal na sede da Cia de Dança Humaniza, todas precedidas pela definição prévia de data e horário.

As entrevistas ocorreram em dois momentos, ao início e ao término do período de seis meses, sendo que ao início foram entrevistadas as mães buscando identificar as características prévias das crianças, e ao final do período de seis meses de prática foram entrevistadas as mães novamente e a professora de dança para identificar as possíveis alterações proporcionadas pela prática, todas gravadas e transcritas na íntegra.

Os dados obtidos foram interpretados pela técnica da análise de conteúdo. Segundo Bardin (1977), por meio dessa técnica são analisados discursos diversificados buscando desvendar o que está oculto em cada fala, decompondo-os em categorias de elementos que apresentam significado para o tema estudado. Para isso, são realizadas três fases: em um primeiro momento há a pré-análise dos dados, explorando por meio da leitura o material obtido; em um segundo momento são organizadas as ideias encontradas; e, por fim, há uma fase de tratamento, inferência e interpretação dos dados, na qual os resultados são apresentados de forma categorizada com destaque para as principais informações.

\section{Resultados}


Com o propósito de atender aos objetivos deste estudo, apresentamos a sequência das categorias identificadas nas entrevistas das mães e da professora de dança separadas por período inicial e final em relação aos seis meses de aulas de dança e expressão corporal.

Início do período de seis meses de aulas

Partindo dos indicadores retirados dos discursos das mães, identificamos as categorias principais iniciais:

QUADRO 1 - Categorias identificadas nos discursos das mães anteriormente aos seis meses de aulas

\begin{tabular}{|l|l|}
\hline Categorias da Mãe C1 & Categorias da Mãe C2 \\
\hline Malcriado & Agressivo \\
Traumatizado & Hiperativo \\
Dificuldade em arrumar escola (problemas & Incapaz de aprender \\
de relacionamento com os colegas) & Possui características de autismo \\
Incapaz de se alfabetizar & \\
Agressivo & \\
\hline
\end{tabular}

Fonte: Elaborado pelos autores, 2019.

Final do período de seis meses de aulas

Partindo dos indicadores retirados dos discursos das mães, identificamos as categorias principais finais:

QUADRO 2 - Categorias identificadas nos discursos das mães após os seis meses de aulas

\begin{tabular}{|l|l|}
\hline Categorias da Mãe C1 & Categorias da Mãe C2 \\
\hline Lindo & Emocionada \\
Talentoso & Surpresa com sua capacidade \\
& Gostaria de mostrar aos professores da \\
& escola a capacidade do filho \\
\hline
\end{tabular}

Fonte: Elaborado pelos autores, 2019.

Já em relação à professora, esta possuía 22 anos de experiência em ministrar dança e atividades de expressão corporal para pessoas com deficiência, era bailarina com formação em Pedagogia, Especialização e Mestrado em Atividade Motora Adaptada, específicos na área de dança para pessoas com deficiência. No seu discurso, identificamos como categorias principais:

QUADRO 3 - Categorias identificadas no discurso da professora de dança após seis meses de aulas

\begin{tabular}{|l|l|}
\hline Categorias da Professora sobre C1 & Categorias da Professora sobre C2 \\
\hline Talentoso & Concentrado \\
Expressivo & Sensível \\
Criativo & Curioso \\
Necessita de apoio & Prestativo (gosta de ajudar) \\
\hline
\end{tabular}


Fonte: Elaborado pelos autores, 2019.

\title{
Discussão
}

Principiando uma reflexão sobre os dados, pode-se notar que as falas das mães anteriormente às atividades de seus filhos com a dança e expressão corporal destacaram aspectos negativos do comportamento destes e também do seu desempenho na aprendizagem, aludindo inclusive ao contexto da escola regular:

Ele é assim, meio malcriado, não sei como ele não apanha na escola... (MÃE C1)

\begin{abstract}
Meu filho é muito agressivo na escola e também é hiperativo, não para um minuto, os professores vivem reclamando dele. Ele não aprende, a psicóloga disse que ele tem, traços de autismo, quero por ele em alguma atividade como a dança para ver se ele acalma um pouco, se concentra e para um pouco de cair e se bater nas coisas e nos amigos. (MÃE C2)
\end{abstract}

Essas referências depreciativas, especialmente em relação à $\mathrm{C} 2$, podem ser associadas às constantes avaliações psicológicas e médicas que comumente são submetidas às crianças que apresentam algum desvio no quadro esperado para a aprendizagem, às quais muitas vezes impõem diagnósticos permeados por rótulos negativos.

O discurso materno veio ao encontro do estudo de Batista e Mantoan (2007), o qual apontou que o impedimento em compreender uma dificuldade ou deficiência acarreta consequências indeléveis na maneira de lidar com a condição e com quem a possui. A criança $\mathrm{C} 1$ apresentou dificuldades de socialização e foi rotulada a nunca se alfabetizar. Em paralelo, as dificuldades encontradas na escola da criança C2 levaram-na a tomar medicamentos e a carregar rótulos dos mais variados.

É implícito que a falta de conhecimento e de preparo dos profissionais que atuaram com essa população ao longo da sua vida tem dificultado o desenvolvimento qualitativo dessas crianças e corroborado com a manutenção e a ampliação das dúvidas e insegurança da família em relação às potencialidades e características da criança.

Tais conflitos geralmente têm início no diagnóstico da deficiência das crianças pelos profissionais, uma vez que a maior parte das famílias possui desconhecimento sobre as condições de seu filho e sobre como lidar com elas. Sá e Rabinovich (2006) apontaram para a importância do cuidado no momento de revelação do diagnóstico, já que este momento será para muitos pais a linha decisória entre um sonho idealizado no passado e um futuro real diferente que os espera. Em contrapartida, a atitude do profissional tem sido desenhada pela falta de envolvimento e apoio médico necessários à família para a sua adaptação à situação vivenciada e para a tomada de condutas em relação aos cuidados da criança. De forma geral, muitos profissionais não se encontram preparados para lidar com as questões relacionadas à deficiência, apresentando-se imparcialmente e não ressaltando os aspectos positivos da criança ao falar com os pais sobre o diagnóstico, quadro clínico ou prognóstico dessas crianças (FERRARI; MORETE, 2004).

Para além do diagnóstico, os profissionais seguintes a trabalharem com essa criança parecem ainda não ser de todo capacitados para esse atendimento. Apesar do estabelecimento da educação inclusiva no contexto brasileiro, com o direito de todas as crianças a receberem um atendimento de qualidade nas atividades socioeducativas, de acordo com Bernardo e Soares (2012), a dificuldade de ensino-aprendizagem encontrada e diagnosticada no contexto da educação brasileira, seja pelos possuidores de deficiência intelectual ou de transtornos de aprendizagem, ainda permanece como um tema controverso com professores, médicos, fono- 
audiólogos, psicopedagogos e outros especialistas apresentando opiniões conflitantes em relação às suas causas e inseguras quanto à eficiência de sua intervenção.

Para Maciel (2012), a maior barreira no relacionamento entre educadores e crianças com dificuldades de aprendizagem ocorre por falta de uma visão global do ser humano, pois os professores mantêm uma tendência em analisar apenas aspectos pontuais da criança que se relacionam ao entendimento do conteúdo da disciplina lecionada. Por conseguinte, de acordo com Bernardo e Soares (2012), professores e profissionais da saúde buscam fatores que justifiquem tal dificuldade, fatores estes que muitas vezes são discriminatórios e preconceituosos, acabando por estigmatizar os alunos que possuem a dificuldade, como ao rotular alguns alunos como preguiçosos e desinteressados por falta de conhecimento sobre o aluno e suas características individuais. Esses rótulos são informados às famílias, que acabam por internalizar tais características da criança como inalteráveis.

Apesar de todo esse contexto conflituoso, com a realização do programa de atividades corporais proposto neste estudo foram obtidas contribuições relevantes aos comportamentos e aprendizagens das crianças participantes.

As mães, que a princípio destacavam os aspectos negativos dos filhos, passaram a vê-los de uma maneira mais positiva, com sinais de uma mudança de olhar sobre os mesmos a partir do momento no qual estes explicitaram suas habilidades, principalmente por meio da apresentação coreográfica ao final do período de seis meses de aulas:

Que lindo!!! Meu Deus, meu filho é talentoso, posso dançar com ele um dia destes? (MÃE C1 APÓS O ESPETÁCULO)

Não acredito, estou muito emocionada nunca pensei que ele conseguisse fazer isto, estou sem palavras, queria que os professores da escola viessem ver isto aqui, ele parece outro menino. (MÃE C2 APÓS O ESPETÁCULO)

Esses discursos das mães foram corroborados pelas falas da professora de dança após o período dos seis meses de aulas:

O C1 nasceu para a arte, expressão, movimento, ele se expressa muito bem é criativo, nós temos que dar apoio para que ele se sinta à vontade para se apresentar em público. Na última apresentação ele veio com uma carta que ele mesmo escreveu e também com a letra de uma música para me mostrar; é uma música que ele gosta e quer dançar. (PROFESSORA DE DANÇA SOBRE C1)

Ele adora movimento é concentrado, sensível, extremamente curioso quer explorar tudo, os movimentos, os instrumentos da sala, acho que é por isto que o chamam de hiperativo. Ele tem sede de conhecimento, às vezes se coloca na hora errada, mas conversando ele entende, está se disciplinando cada dia mais..., percebo que ele gosta de ajudar os colegas. (PROFESSORA DE DANÇA SOBRE C2)

No contato com a expressão artística ambos transcenderam suas aparentes limitações, confirmadas e impostas por profissionais e pelas próprias mães que internalizam os diagnósticos e as percepções dos profissionais envolvidos no contexto médico, educativo e social de seus filhos.

As atividades com o movimento corporal e a dança envolveram um processo avaliativo qualitativo continuado que considerou todos os avanços e potenciais individuais. Neste sentido, constata-se nos dois casos o que afirmaram as autoras Moysés e Collares (1997), que a dança pode auxiliar no desenvolvimento das habilidades e comportamentos dos alunos, sendo imprescindível que haja uma superação do vigente não reconhecimento de atividades expressivas corporais como relevantes ao contexto educativo social, o qual ainda privilegia pre- 
dominantemente aspectos cognitivos pontuais respondentes aos instrumentos de avaliação pré-determinados.

Miranda (2008) ratificou esses entendimentos ao explicitar que, proporcionando um trabalho que aceita e valoriza as diferenças individuais, a dança torna-se um instrumento de inspiração contribuinte ao desenvolvimento global de uma pessoa.

Percebe-se que as atividades com a dança contribuíram para o despertar das possibilidades dos alunos que não foram reconhecidas em outros contextos, como o escolar, conforme relato das mães, possibilitando a ausência de julgamentos e fortalecendo a autoestima destas crianças, especialmente ao ser considerada a importância do espetáculo aberto ao público realizado, dos aplausos, da conquista do fazer bem, dos elogios e dos reforços positivos.

Os benefícios alcançados por meio dessa intervenção prática podem ser associados a dois principais fatores: às atividades de dança e expressão corporal em si mesmas, e a capacitação do profissional para o trabalho com pessoas com deficiências que conduziu as aulas.

Em relação às expressões artísticas, essas atividades ofereceram um espaço onde as crianças puderam expressar sua criatividade e mostrar suas potencialidades. Ao aceitar cada corpo e cada identidade com as suas personalidades, os movimentos corporais e a dança constituíram um processo de interação, ensino e aprendizagem mediados pela experiência corporal e pelo envolvimento das emoções e sensações, que por sua vez, ofereceram possibilidades de participação, liberdade de criação e um estímulo para a busca de autonomia. Neste espaço, os alunos aprenderam uns com os outros, compartilhando suas histórias, culturas, gostos, dificuldades e habilidades.

Confirmando essa perspectiva, Boissière e Kintzler (2006, p. 7) esclareceram que a dança pode oportunizar um espaço onde julgamentos dão lugar às descobertas, pois ela não é somente uma arte do gesto, mas uma arte que faz o gesto, uma arte que pode desmistificar qualquer preconceito existente.

No entanto, para que os benefícios dessas atividades expressivas sejam usufruídos pelos alunos, Moysés e Collares (1997) discorreram que é necessário que a atividade seja ensinada com o professor considerando as expressões diferentes oriundas de cada aluno com sua cultura, experiências e saberes. Por sua vez, Soares (2003) explanou que o sucesso do processo de ensino-aprendizagem ocorre apenas por um processo significativo, no qual o conhecimento a ser aprendido e apreendido faça sentido para o aluno, seja na sua existência educacional, social ou cotidiana.

De acordo com Soares (2003), o processo de ensino-aprendizagem é construído sócio intencionalmente entre educador/educando/meio para proporcionar a construção de um dado conhecimento. Segundo Freinet (2004), tal processo deve ser fundamento pelo entendimento e respeito docente sobre o conhecimento prévio da criança e seu contexto histórico-familiar, social e cultural.

O fato da professora possuir uma qualificação e experiência profissional específica no trabalho com pessoas com dificuldades e deficiências mostrou ser contributivo com o alcance dos resultados positivos ao proporcionar um processo de ensino-aprendizagem adequado às diversidades dos alunos, respeitando suas próprias construções de movimentos e ritmos de interação com o conteúdo, não impondo padrões de gestos a serem executados de forma minuciosamente técnica.

Essa atuação docente apresentou-se em consonância com o percurso educativo proposto por Zacharias (2008), uma vez que, considerando que nenhum aluno terá o mesmo caminhar no processo de ensino-aprendizagem, os professores devem personificar o ensino deliberadamente para melhor dar conta das necessidades dos alunos, em um olhar para os alunos com dificuldade de aprendizagem ou deficiência intelectual vislumbrando novas possibilidades, soluções criativas, com propostas que facilitassem a expressão, a criatividade e a afetividade. 
E, para isso, a capacitação e preparo profissional não apenas inicial, mas contínuo, sobre o público com quem se trabalha é imprescindível. Carrillo (2013) e Salerno (2014) apontaram que a formação deve ser permanente e sustentada por um currículo de graduação que absorva o conhecimento sobre as diversidades em todas as suas disciplinas, associando conceitos biológicos com socioculturais e pedagógicos de forma a vincular as teorias com as intervenções práticas e, na sequência, com o profissional buscando uma capacitação contínua para superar as possíveis dificuldades e se qualificar perante as diferentes necessidades dos seus alunos.

Concluímos, portanto, que o oferecimento de vivências e atividades expressivas como a dança e a expressão corporal contribuiu com o desenvolvimento do processo de ensinoaprendizagem de pessoas com deficiência intelectual e transtornos de aprendizagem.

Os casos apresentados neste estudo merecem ser acompanhados continuamente buscando um repensar das práticas pedagógicas e do potencial humano, assim como novas pesquisas necessitam ser estruturadas especificando os itens identificados como relevantes por esse estudo para a prática corporal de pessoas com deficiência - como as metodologias mais adequadas para o desenvolvimento dessas práticas com essa população, a adequação da formação docente para esse trabalho, o relacionamento entre família e profissionais que atuam com crianças com deficiência, dentre outros. As atividades de dança e expressão corporal apareceram como um possível caminho para facilitar os processos de ensino-aprendizagem dos demais contextos, seja escolar ou de práticas sociais, sendo imprescindível que essas práticas sejam valorizadas no grupo social.

\section{Referências}

AAIDD. Intellectual disability: definition, classification, and systems of supports. 11. ed. 2010.

ALESSI, A.; ZOLBROD, S. Manual para certificação de professores. Florianópolis: Danceabillity, 2011.

ALMEIDA, M. A. Apresentação e análise das definições de deficiência. Revista de Educação, Campinas, São Paulo, v. 1, n. 6, p. 33-48, jul. 2004.

AMERICAN PSYCHIATRIC ASSOCIATION. Manual diagnóstico e estatístico de transtornos mentais. 5. ed. Porto Alegre: Artmed, 2014.

BARDIN, L. Análise de conteúdo. Lisboa: Edições 70, 1977.

BARRETO, D. Dança, ensino, sentidos e possibilidades na escola. Campinas, SP: Autores Associados, 2004.

BATISTA, C. A. M.; MANTOAN, M. T. E. Atendimento Educacional Especializado em Deficiência Mental. In: GOMES, A. L. L. et al. Deficiência Mental. São Paulo: MEC/SEESP, 2007.

BERNARDO, B. A.; SOARES, A. Professores que rotulam. Revista EnsiQLopédia, Osório, RS, v. 9, n. 1, p. 77-81, out. 2012.

BOISSIÈRE, A.; KINTZLER, C. Approche philosophique du geste dansé: de 
l'improvisation à la performance. Villeneuve d'Ascq: Press Universitaires du Septentrion, 2006.

CARRILlO, P. A disciplina educação física adaptada nas Universidades do Chile. 2013. 167 f. Tese (Doutorado em Educação Física) - Faculdade de Educação Física, Universidade Estadual de Campinas, Campinas, São Paulo, 2013.

CARVALHO, C. L.; ARAÚJO, P. F.; SALERNO, M. B. As concepções de inteligência e a influência na inclusão da pessoa com deficiência intelectual na educação física escolar. In: VIII ENCONTRO DA ASSOCIAÇÃO BRASILEIRA DE PESQUISADORES EM EDUCAÇÃO ESPECIAL, 2013, Londrina. Anais... Londrina: Congresso Brasileiro Multidisciplinar de Educação Especial, 2013. v. 1. p. 1442-1453.

FERRARI, J. P.; MORETE, M. C. Reações dos pais diante do diagnóstico de paralisia cerebral em crianças com até 4 anos. Cadernos de Pós-graduação em Distúrbios do Desenvolvimento, São Paulo, v. 4, n. 1, p. 25-34, 2004.

FREINET, C. Pedagogia do bom senso. 7. ed. São Paulo: Martins Fontes, 2004.

GOULD, S. J. A Falsa Medida do Homem. São Paulo: Martins Fontes, 1991.

HARLOS, F. E.; HARLOS, F. C. G.; DENARI, F. E. Origens da categoria "deficiente" e da educação especial (re)pensada. Revista Géfyra, São Miguel do Iguaçu, Paraná, v. 1, n. 2, p. 95-105, jul./dez. 2012.

KUNZ, E. Educação física crítico-emancipatória: com uma perspectiva da pedagogia alemã do esporte. Ijuí, RS: Ed. Unijuí, 2006.

LABAN, R. Dança educativa moderna. São Paulo: Ícone, 1990.

LEONTIEV, A. M. A brincadeira é a atividade principal da criança pequena. In: Fundação Roberto Marinho. Professor da pré-escola. Rio de Janeiro: FAE, 1991.

LUCKASSON, R. et al. Mental retardation: Definition, classification, and systems of supports. 9. ed. Washington DC: American Association on Mental Retardation, 1992.

LUCKASSON, R. et al. Mental Retardation: Definitions, Classification and Systems of Supports. 10th Edition, AAMR, 2002.

MACIEL, A. G. Motivação e intervenção em estratégias de aprendizagem para compreensão leitora. 134 f. 2012. Dissertação (Mestrado em Educação) - Universidade Estadual de Londrina, Londrina, Paraná, 2012.

MANTOAN, M. T. E. Educação inclusiva: orientações pedagógicas. In: FÁVERO, E. A. G.; PANTOJA, L. de; MANTOAN, M. T. E. Atendimento educacional especializado: Aspectos legais e orientações pedagógicas. São Paulo: MEC/SEESP, 2007.

MARQUES, I. A. Ensino de dança hoje: textos e contextos. São Paulo: Cortez, 1999. 
MIRANDA, R. Para incluir todos os corpos. In: CALAZANS, M. J.; CASTILHO, J.; GOMES, S. (Org.). Dança e Educação em Movimento. São Paulo: Cortez, 2008.

MOYSÉS, M. A. A.; COLLARES, C. L. Inteligência abstraída, crianças silenciadas: as Avaliações de Inteligência. Psicologia USP, São Paulo, v. 8, n. 1, p. 63-89, 1997. Disponível em: <www.scielo.br/scielo.php?script=sci_arttext\&pid=S0103-65641997000100005>. Acesso em: 09 ago. 2017

OAKLAND, T.; HARRISON, P. L. Adaptive Behavior Assessment System-II. Cambridge: Academic Press, 2008.

OMS. Classificação Internacional de Funcionalidade, Incapacidade e Saúde. Lisboa: Organização Mundial de Saúde, Direção Geral de Saúde, 2004.

PAULON, S. M. Documento Subsidiário à política de inclusão. 2. ed. Brasília: Ministério da Educação, Secretaria de Educação Especial, 2007.

PUTTINI, R. F.; JUNIOR, A. P. Além do mecanicismo e do vitalismo: a "normatividade da vida" em Georges Canguilhem. Physys: Revista de saúde coletiva, Rio de Janeiro, v. 17, n. 3, p. 451-464, 2007. Disponível em: <http://www.scielo.br/scielo.php?pid=S010373312007000300003\&script=sci_arttext >. Acesso em: 06 ago. 2017.

SÁ, S. M. P.; RABINOVICH, E. P. Compreendendo a família da criança com deficiência física. Revista Brasileira de Crescimento e Desenvolvimento Humano, São Paulo, v. 16, n. 1, p. 68-84, 2006.

SALERNO, M. B. A formação em educação física e o trabalho com a pessoa com deficiência: percepção discente. 2014. 184 f. Tese (Doutorado em Educação Física) - Faculdade de Educação Física, Universidade Estadual de Campinas, Campinas, São Paulo, 2014.

SASSAKI, R. K. Atualizações semânticas na inclusão de pessoas: Deficiência mental ou intelectual? Doença ou Transtorno Mental? Revista Nacional de Reabilitação, ano IX, n. 43, mar./abr. 2005, p. 2 9-10. Disponível em: $<$ http://www.ppd.caop.mp.pr.gov.br/modules/conteudo/conteudo.php?conteudo=343>. Acesso em: 28 ago. 2017.

SHIMAZAKI, E. M.; TSUKAMOTO, N. M. S. O atendimento educacional especializado para alunos com deficiência intelectual. Maringá, Paraná: EDUEM, 2012.

SHOGREN, K. et al. Effect of Intervention with the Self-Determined Learning Model of Instruction on Access and Goal Attainment. Remedial Spec Educ., v. 33, n. 5, p. 320-330, sep. 2012. Disponível em: <https://www.ncbi.nlm.nih.gov/pubmed/24771963>. Acesso em: 28 ago. 2017.

SHOGREN, K. et al. Intellectual disability: definition, classification and systems of support, Washington (DC): AAIDD, 2010.

SOARES, D. C. R. Os vínculos como passaporte da aprendizagem: um encontro D'EUS. Rio de Janeiro: Caravansarai, 2003. 
ZACHARIAS, V. L. C. O que são realmente dificuldades de aprendizagem? São Paulo, 2008. Disponível em: <http://www.centrorefeducacional.com.br/adificeis.htm>. Acesso em: 07 jan. 2017.

Recebido em: 04/09/2017

Revisado em: 04/10/2018

Aprovado em: 29/10/2018

Endereço para correspondência:

keylafe@gmail.com

Keyla Ferrari Lopes

Faculdade de Educação Física, Universidade Estadual de Campinas

Cidade Universitária Zeferino Vaz

Barão Geraldo,

13083-970 Campinas - SP, Brasil 